\title{
CYPRIPEDIUM CALCEOLUS GERMINATION IN SITU: SEED LONGEVITY, AND DORMANCY BREAKAGE BY LONG INCUBATION AND COLD WINTERS
}

\author{
HANNE N. RASMUSSEN ${ }^{1}$ and HENRIK Æ. PEDERSEN ${ }^{2}$ \\ ${ }^{1}$ Forest \& Landscape, Life faculty, University of Copenhagen. E-mail: hnr@life.ku.dk. Tel.: +45 35331703; Fax: +45 35331508 \\ 2 Botanical Garden and Museum, Natural History Museum of Denmark, University of Copenhagen
}

\section{ABSTRACT}

A successful in situ germination experiment with Cypripedium calceolus, the European Lady's slipper, is reported here for the first time. The seeds originated from controlled pollinations within and between two closely related Danish populations. The seeds were sown ripe in seed packets in proximity of mother plants. Germination was first observed after $4.5 \mathrm{y}$ in the ground, following two successive cold and snowy winters, and only in one population. Seedlings expanded through the sides of the broken testa and were hair-less. A corresponding set of seeds, germinated in vitro as asymbiotic controls, responded positively to repeated cold stratifications after long incubation, suggesting that time (leaching?) and chilling are dormancy breakage factors.

Keywords: microseeds, orchid seedling, symbiotic germination

\section{Background}

Cypripedium calceolus, the European Lady-Slipper, in Denmark only occurs in two localities about $4 \mathrm{~km}$ apart. One population is in slow decline, the other in rapid increase (Pedersen et al. 2012). In search of an explanation, we carried out a study of genetic diversity, seed set, compatibility and germination, comparing the two sites. The study included lengthy germination experiments in situ that are reported below.

\section{Materials and Methods}

Pollinations were carried out by selfing, cross pollination within populations, and cross pollination between populations. Referring each type of cross to the locality of the seed parent we obtained 6 different seed lots. Fruits were produced in triplicate (Pedersen et al. 2012). For field sowing (according to the method of Rasmussen and Whigham 1993) we used mix of the three fruits. Mature seeds were harvested in late october and planted out on

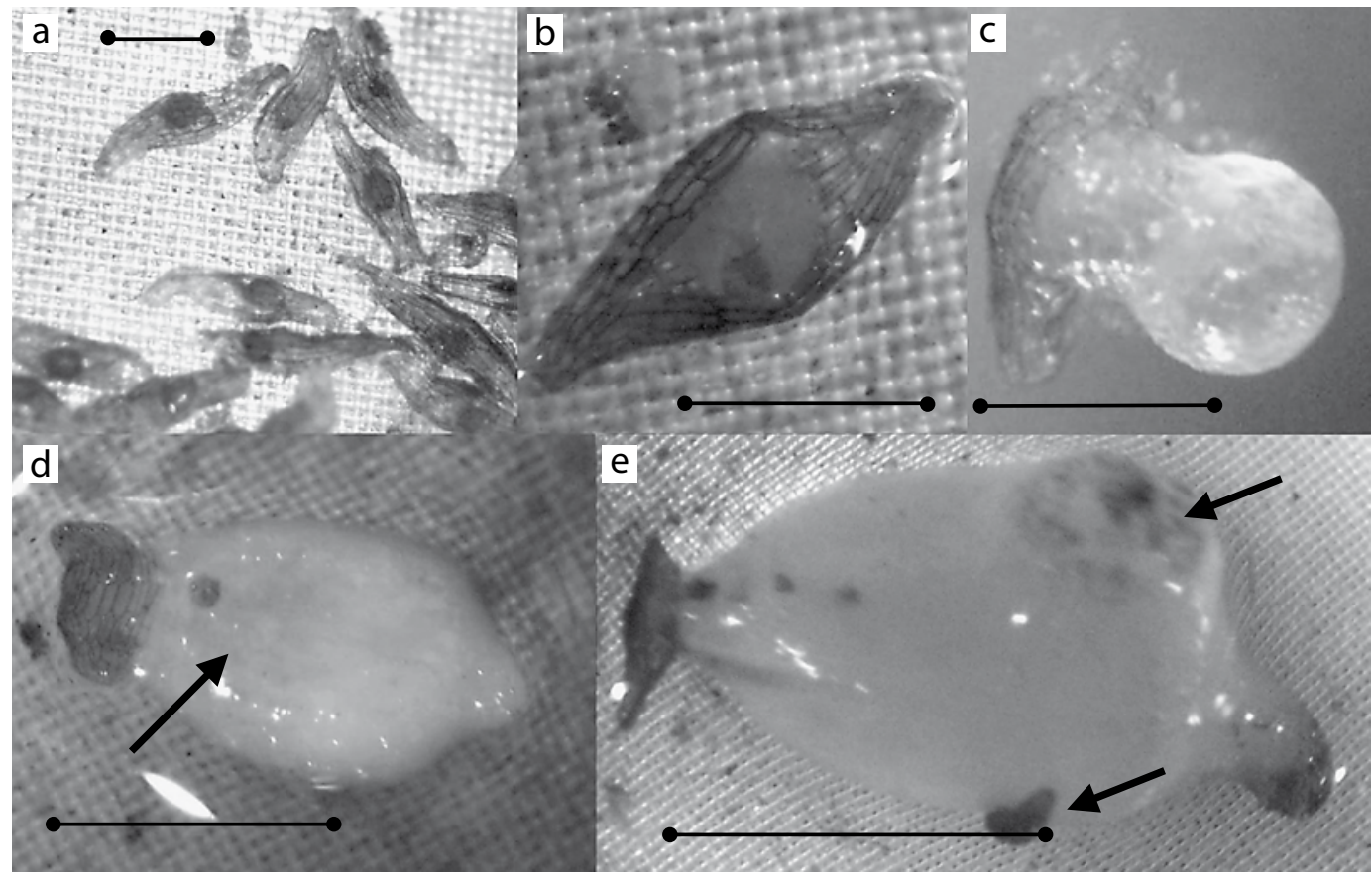

Fig. 1 Stages in germination of Cypripedium calceolus, after $4.5 \mathrm{y}$ in the ground (= $54 \mathrm{mo}$ ). All observed in July 2010 . a. Embryo and testa of most seeds remain intact. b. Testa broken by a longitudinal slit. c. Seedling in globular stage, emerging through the side of testa, d. Shoot tip differentiated and micropylar end with yellowish tinge to suggest mycorrhizal infection (arrow). e. Oldest seedling stage seen, with primordia for adventitious roots (arrows). Scale bars: a-b-c: $0.5 \mathrm{~mm}$, d: $1 \mathrm{~mm}$, e: $2 \mathrm{~mm}$. 
the sites in seed packets in Dec 2005. There were three sowing plots at each locality, and 6 times 6 seed packets in each, representing 6 replicates of every seed lot. Samples were checked about once a year. After the third year's unsuccessful sampling we decided to replace seed packets after checking for germination. The seed packets were kept cool and lightly humid, up to about 10 days before being returned to the sowing site. Packets were marked so that they were returned to the original plot, and marked to show that they had been excavated before.

\section{Results}

Germination in situ was first observed in June 2010, after 54 months in the ground, and after two successive cold and snowy winters. Germination was only sparse, only one packet from the thriving population, and ungerminated seeds continued to look healthy (Fig. 1a). The successful packet had been excavated once previously. Seedling stages ranged from broken testa (Fig. 1b) to initial root development (Fig. 1e). They expanded sideways out through the broken testa, and there were no root hairs. The micropylar end of seedlings contained fungal pelotons (Fig. 1d-e), suggesting that initial infection took place through micropyle.

\section{Discussion}

This appears to be the first field germination in the European Lady-slipper which is observed with an approximate timing from dispersal. The field results suggest a requirement for successive cold treatments and long incubation times. This interpretation is supported by asymbiotic germinations in vitro of the same seed lots (Pedersen et al. 2012), where germination was sporadic $(2.2 \%)$ after the first cold stratification, and considerably higher (30\%) after the second, in a trial that lasted 115 weeks. The results also demonstrate longevity in the hydrated seeds.

\section{REFERENCES}

Pedersen HÆ, Rasmussen HN, Kahandawala I, Fay MF (2012) Online. Genetic diversity, compatibility patterns and seed quality in isolated populations of Cypripedium calceolus (Orchidaceae). Conservation Genetisc DOI 10.1007/s10592-011-0267-0.

Rasmussen HN, Whigham DF (1993) Seed ecology of dust seeds in situ: a new study technique and its applicaton in terrestrial orchids. Amer J Bot 80: 1374-1378. 